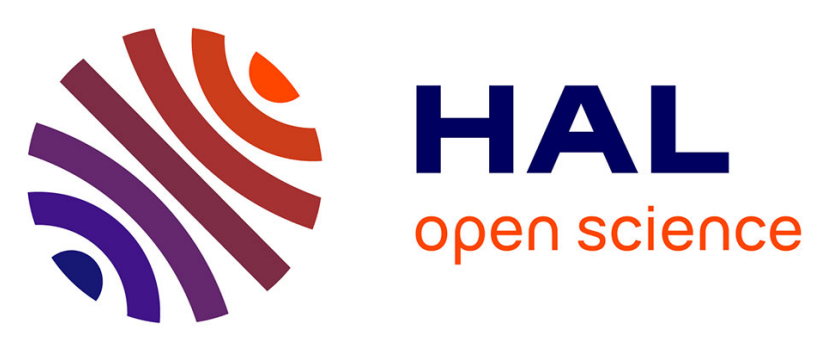

\title{
Lobular and non-lobular breast cancers differ regarding axillary lymph node metastasis: a cross-sectional study on 4,292 consecutive patients
}

T. Vandorpe, A. Smeets, B. Calster, K. Hoorde, K. Leunen, F. Amant, Ph. Moerman, K. Deraedt, O. Brouckaert, S. Huffel, et al.

\section{To cite this version:}

T. Vandorpe, A. Smeets, B. Calster, K. Hoorde, K. Leunen, et al.. Lobular and non-lobular breast cancers differ regarding axillary lymph node metastasis: a cross-sectional study on 4,292 consecutive patients. Breast Cancer Research and Treatment, 2011, 128 (2), pp.429-435. 10.1007/s10549-0111565-4 . hal-00640457

\section{HAL Id: hal-00640457 https://hal.science/hal-00640457}

Submitted on 12 Nov 2011

HAL is a multi-disciplinary open access archive for the deposit and dissemination of scientific research documents, whether they are published or not. The documents may come from teaching and research institutions in France or abroad, or from public or private research centers.
L'archive ouverte pluridisciplinaire HAL, est destinée au dépôt et à la diffusion de documents scientifiques de niveau recherche, publiés ou non, émanant des établissements d'enseignement et de recherche français ou étrangers, des laboratoires publics ou privés. 


\section{Lobular and non-lobular breast cancers differ regarding axillary lymph node metastasis: a cross-sectional study on}

4292 consecutive patients

T Vandorpe ${ }^{* 1,2}$, A Smeets* ${ }^{* 1}$, B Van Calster ${ }^{2,3}$, K Van Hoorde ${ }^{2,3}$, K Leunen ${ }^{1,4}$, F Amant $^{1,4}$, Ph Moerman ${ }^{5}$, K Deraedt ${ }^{5}$, O Brouckaert ${ }^{4}$, S Van Huffel ${ }^{2}$, H Wildiers ${ }^{1}$, MR Christiaens $^{1}$, P Neven ${ }^{1,4}$

(*) equal contribution

${ }^{1}$ Multidisciplinary Breast Centre, University Hospitals Leuven, Belgium

${ }^{2}$ Department of Electrical Engineering (ESAT-SISTA), Katholieke Universiteit Leuven, Belgium

3 IBBT/K.U. Leuven Future Health Department, Katholieke Universiteit Leuven, Belgium

${ }^{4}$ Division of Gynecologic Oncology, University Hospitals Leuven, Belgium

${ }^{5}$ Department of Pathology, University Hospitals Leuven, Belgium

Dr. Ann Smeets

ann.smeets@uzleuven.be

$\mathrm{T}+3216346864$

F +32 16 346834 
Lobular and non-lobular breast cancers differ regarding axillary lymph node metastasis: a cross-sectional study on 4292 consecutive patients

T Vandorpe ${ }^{* 1,2}$, A Smeets* ${ }^{* 1}$, B Van Calster ${ }^{2,3}$, K Van Hoorde ${ }^{2,3}$, K Leunen ${ }^{1,4}$, F Amant $^{1,4}$, Ph Moerman ${ }^{5}$, K Deraedt ${ }^{5}$, O Brouckaert ${ }^{4}$, S Van Huffel ${ }^{2}$, H Wildiers ${ }^{1}$, MR Christiaens $^{1}$, P Neven $^{1,4}$

(*) equal contribution

${ }^{1}$ Multidisciplinary Breast Centre, University Hospitals Leuven, Belgium

${ }^{2}$ Department of Electrical Engineering (ESAT-SISTA), Katholieke Universiteit Leuven, Belgium

3 IBBT/K.U. Leuven Future Health Department, Katholieke Universiteit Leuven, Belgium

${ }^{4}$ Division of Gynecologic Oncology, University Hospitals Leuven, Belgium

${ }^{5}$ Department of Pathology, University Hospitals Leuven, Belgium

Acknowledgments: BVC is a postdoctoral fellow of the Research Foundation - Flanders (FWO). KVH is supported by a grant from the Agency for Innovation by Science and Technology (IWT).

$\underline{\text { Abstract }}$

Background 
Invasive lobular carcinoma (ILC) accounts for $8 \%$ to $14 \%$ of all breast cancers and carries distinct prognostic and biologic implications. The goal of our study was to investigate the impact of lobular histology on axillary lymph node $(\mathrm{ALN})$ involvement.

\section{Patients and methods}

This is a cross-sectional study of 4292 consecutive patients surgically treated for breast carcinoma at the University Hospitals Leuven. Logistic regression analysis was used to relate ILC to lymph node involvement while controlling for the following clinicopathologic features: tumor size, multifocal disease, tumor grade, lobular subtype and the combined steroid and Her2 status. Odds ratios (OR) and 95\% confidence intervals (CI) were computed. A subgroup analysis was performed for patients that underwent a sentinel lymph node (SLN) procedure.

\section{Results}

The observed incidence of ILC was 13\%. ILCs were larger, were more often grade II, multifocal, steroid receptor positive and Her2 negative, and tended to be present in older patients. Incidence of ALN involvement was $42.0 \%$ for ILCs versus $38.3 \%$ for other tumors (OR 1.17, 95\% CI 0.97-1.40). For the SLN subgroup, ILCs were less often ALN positive than non-ILCs (20.5\% versus $28.3 \%$, OR $0.66,95 \%$ CI: $0.41-1.00)$. In the multivariable analysis, the lobular subtype was identified as less likely to have ALN involvement (adjusted OR 0.66, 95\% CI 053-0.82). The analysis for the SLN subgroup showed comparable results (adjusted OR 0.49, 95\% CI 0.30-0.78).

\section{Conclusion}

The present study has demonstrated that the lobular subtype is an independent predictor of lymph node involvement with ILC having a lower incidence of involved lymph nodes. The mildly higher incidence of ALN metastasis in lobular cancers in univariable analysis is not due to the lobular subtype, but due to confounding factors that interact with lymph node involvement.

\section{Keywords}

Invasive lobular carcinoma - breast cancer - lymph node 


\section{Introduction}

Lymph node involvement is the most important prognostic factor in breast cancer. It is a multifactorial event determined by tumor and patient characteristics. Variables associated with lymph node metastasis are tumor size, grade, lymphovascular invasion (LVI) multifocality, estrogen receptor (ER), progesterone receptor (PR) and HER-2 status [1].

Invasive lobular carcinoma (ILC) is the second most common type of invasive breast cancer after invasive ductal carcinoma and accounts for $8 \%$ to $14 \%$ of all breast cancer cases [2,3]. ILC is characterized by small, round cells which infiltrate both the stroma in an Indian file pattern and the adipose tissue without desmoplastic reaction, which makes early diagnosis challenging [2]. Absence of E-cadherin expression is considered a characteristic of ILC [3]. The diagnosis of ILC carries distinct prognostic and biologic implications. Differences in clinical behaviour between ILCs and invasive ductal carcinomas have been reported [2-7]. ILCs have a propensity for multifocal and multicentric distribution but also for bilateralism and a particular pattern of metastatic spread. The incidence of ILC is increasing, especially among postmenopausal women using hormone replacement therapy.

The goal of our study was to investigate the impact of lobular histology on lymph node involvement.

\section{Patients and methods}

\section{Design, setting and patients}

This was a retrospective cross-sectional study based on data from patients of the Multidisciplinary Breast Centre of the University Hospitals Leuven, Belgium. This database contains data on 4486 female patients with a primary operable invasive breast cancer from the period between 2000 and 2009. Exclusion criteria were (1) patients who had neoadjuvant systemic therapy (2) patients who never had breast cancer surgery (3) patients whose pathologic assessment was not performed in the University Hospitals Leuven (4) patients with primary metastatic disease. Of the 4486 patients satisfying these criteria, 19 were ER negative and PR positive. We excluded these patients because there is controversy regarding such tumors. There were 175 patients (3.9\% of 4467) with missing data for one or more of the studied variables, most often due to lack of sufficient tumor tissue for correct pathologic assessment of molecular markers. These tumors were excluded for analysis, resulting in a 
dataset of 4292 tumors. Patients that underwent a sentinel lymph node (SLN) procedure ( $\mathrm{n}=1506)$ were defined as a subgroup for which a separate analysis was performed following the analysis on all patients.

\section{Variables studied}

The following variables were examined: age at diagnosis, maximal microscopic tumor size (largest diameter), histology (ILC vs. non-ILC), worst tumor grade, multifocal disease, axillary lymph node (ALN) status, and the combined ER, PR and HER-2/neu status. Histology and multifocal disease were analyzed as dichotomous variables, the combined receptor status as six-level categorical. Determination of tumor grading and ER, PR, and HER-2/neu status was done according to established procedures, which have been described in more detail elsewhere [8]. A breast cancer was allocated to the lobular subtype if more than $90 \%$ of the tumor mass harboured morphological features of the lobular type; this was always confirmed by lack of E-cadherin expression. Tumors with mixed ductal and lobular phenotype were considered as non-ILC. Tumors with a lobular growth pattern with an E-cadherin positive phenotype were classified as non-ILCs. In case of multifocal disease, the largest tumor was used for size and histotype. In case of bilateral breast cancer, both sides were included as separate tumors.

Lymph nodes in an ALN dissection, were examined by H\&E staining using 3 sections per node; according to published guideline, lymph nodes from lobular breast cancers classified as lymph node negative on H\&E were additionally stained with epithelial markers. SLN were routinely examined by serial sectioning and IHC. Isolated tumor cells were classified as lymph node negative.

\section{Statistical Analysis}

First, ILC and non-ILC tumors are compared with respect to grade, combined receptor status, multifocality, age at diagnosis, and tumor size. Kendall's tau test was used for tumor grade, the Mann-Whitney test (i.e. Wilcoxon rank sum) for age and tumor size, and likelihood ratio chi-square tests for the categorical variables. Next, univariable relationships with ALN are investigated using odds ratios (OR) with 95\% CIs. Finally, a multivariable logistic regression model is constructed to assess the independent relationships with ALN using adjusted odds ratios (OR) and 95\% CIs. Covariates included in the multivariable analysis were age, tumor size, multifocal disease, tumor grade, and the combined ER, PR, Her-2 status. Linearity for the continuous predictor variables (age, tumor size and tumor grade) was investigated using generalized additive models based on 
smoothing splines [9]. Goodness-of-fit was assessed using calibration plots that indicate the accuracy of the estimated probabilities of ALN involvement. All analyses were performed using Design package in R version 2.8.1 (www.r-project.org) and using SAS version 9.2 (SAS Institute, Cary, NC, USA).

\section{$\underline{\text { Results }}$}

\section{Univariable analysis}

The incidence of ILC observed in the present study was $13 \%$. Table 1 summarizes the patients and tumor characteristics according to the histologic subtype. There were several apparent differences in tumor characteristics between ILCs and non-ILCs. ILCs were more often grade II, had larger tumor sizes, were more often multifocal, tended to be present in older patients and are more frequently ER+/PR+/Her2-.

The results of the univariable prediction of ALN involvement are shown in Table 2. ILCs were slightly more likely to have ALN involvement compared to non-ILCs (42.0\% vs. $38.3 \%$; OR=1.17; 95\% CI: 0.97-1.40). The overall frequency of lymph node metastasis was 39\%. The following factors were univariably related to a higher probability of lymph node involvement: high tumor grade, larger tumor size, multifocal disease, and a ER-/PR/Her2+ or ER+/PR+/Her2+ profile. No strong effect of age at breast cancer diagnosis on ALN involvement was observed.

The univariable analyses were repeated for the subgroup of 1506 patients that underwent a SLN biopsy, as shown in Table 3. In this subgroup analysis, ILCs were less likely ALN positive than non-ILCs (20.5\% vs. 28.3\%; OR=0.65, 95\% CI: 0.41-1.00). The tumor diameter in the SLN subgroup was significantly smaller than in the non-SLN group with a median tumor size of $17 \mathrm{~mm}$ versus $25 \mathrm{~mm}$ respectively $(\mathrm{p}<0.001)$. Apart from the obvious loss in statistical power, the univariable ORs of age at diagnosis, tumor size, and multifocal disease were comparable to those obtained on all patients. The effect of grade was weaker. The effect of combined receptor status was difficult to compare given the large number of small counts for the SLN subgroup (Table 3).

\section{Multivariable logistic regression}

Multivariable analyses were performed using a logistic regression model to determine whether ILC is an independent predictive factor for lymph node involvement. 
The results of the regression model and corresponding adjusted odds ratios are presented in Table 4. The multivariable model identified the lobular subtype as less likely to have ALN involvement. The odds ratio for ILCs versus non-ILCs is 0.66 (95\% CI: 0.53-0.82) in the multivariable model. The predicted risks of ALN involvement for ILC and non-ILC tumors is illustrated in Figure 1. The plot shows the risk by tumor size while fixing the other covariates at their overall median values: grade 2, unifocal, ER+/PR+/Her-2- tumors for patients who were 58 years old at diagnosis. The plot clearly illustrates that ILC tumors have a smaller chance of ALN involvement.

Multivariable analysis of the subgroup that underwent a SLN procedure confirms the significant lower probability of ALN involvement in ILC tumors as well (OR=0.49; 95\% CI: 0.30-0.78). The results are presented in Table 4.

\section{$\underline{\text { Discussion }}$}

The incidence of ILCs observed in our series of 4292 breast tumors (13\%) is in accordance with the incidence range of $8-14 \%$ reported in the literature [2].

Largely in agreement with other series, patient and tumor characteristics at diagnosis are different for ILC than for non-ILC $[2-4,6,7,10]$. ILC are larger at diagnosis, more often grade II, more often multifocal, are frequently ER+ PR+ Her2- and tend to present in older patients (Table 1). A lower proliferative rate and the lack of a desmoplastic reaction may make ILC impalpable or invisible, explaining why ILC tends to present at older age and as a larger tumor than non-ILCs [3].

We observed more ALN involvement in ILC tumors compared to non-ILC tumors (42.0\% vs. 38.3\%). Prior series comparing lobular and non-lobular tumors are not consistent regarding the incidence of lymph node involvement in lobular tumors. The largest published series including 263408 patients from SEER database, is in line with our results while a large series from Bayer college, including 4140 ILCs and 45169 IDCs, showed no difference in the incidence of lymph node involvement between both groups. Sastre even found a lower incidence of involved lymph nodes in lobular tumors.

In the univariable prediction of ALN involvement in our series, tumor size, multifocality, grade and the molecular markers were significant predictors for lymph node involvement. In contrast, age and lobular histology were not significantly correlated with lymph node involvement in our series. 
In the published studies that address the predictors for ALN metastasis in the pre-SLN and SLN eras, tumor size, age, LVI, and histologic subtype were the variables most commonly described as independently associated with ALN involvement. In SLN studies, the variables associated with SLN metastases were, as expected, quite similar $[6,11,12]$.

To evaluate whether the higher incidence of ALN involvement in lobular tumors is a consequence of the lobular histology or of other covariates that interact with ALN involvement, we built a multivariable model correcting for age, tumor size, tumor grade, multifocality, and the combined ER, PR and Her-2 status. All these covariables differed between lobular and non-lobular tumors and correlated with lymph node involvement. The multivariable logistic regression showed a significantly lower incidence of involved lymph nodes in ILCs compared to nonILCs $(\mathrm{OR}=0.66 ; 95 \%$ CI: 0.53-0.82).

Prior multivariable analyses are not consistent regarding ILC as an independent predictor for lymph node involvement. In the bulk of the literature, the lobular subtype is not an independent predictor for lymph node involvement $[11,13-16]$. It is important to keep in mind that most of these studies only included patients eligible for the sentinel lymph node procedure (clinical node negative, smaller tumors, unifocal). A lower probability of ALN metastasis for ILC against ductal was shown by Viale in a large series of 4351 although not significant $(\mathrm{OR}=0.84 ; 95 \% \mathrm{CI}: 0.65-1.07)$.

There can be several reasons why ILCs might be less likely ALN positive than non-ILCs.

Firstly, the uniform appearance of bland tumor cells that lack cellular atypia and often have a low mitotic rate, makes the lobular carcinoma cells more difficult to detect in metastatic lymph nodes [17]. The reported higher rate of false-negative lymph nodes by histologic examination in lobular carcinomas could cause a general understaging of the histologic type at the time of surgery. In our series IHC was used to assess ALN of all lobular tumors when routine H\&E was negative. While contribution of IHC over H\&E to improve lymph nodal staging in ILC remains controversial [18, 19], one could assume the possibility of a higher false negative rate in the nonILC group since IHC was not performed in these cases. Therefore, we might even be underestimating differences in ALN involvement between ILC and non-ILC.

In the subgroup analysis of patients that underwent a sentinel procedure however, all sentinel lymph nodes, ILC and non-ILC, were examined by enhanced pathology (serial sectioning and immunohistochemistry), reducing the 
chance of underestimating the differences in lymph node involvement due to different pathological assessment. In this subgroup analysis, patients with a lobular tumor were less likely to be lymph node positive, strengthening our finding that the higher incidence of lymph node involvement in lobular tumors in univariable analysis might be due to confounding variables such as tumor size and occurrence of multifocal disease rather than the lobular subtype as such. This idea is supported by the fact that in the sentinel subanalysis, an inherently and at least partially stratified subgroup concerning tumor size (as mainly small tumors are included for the SLN procedure), SLN involvement is lower in ILC than in non-ILC (20.5\% and 28.3\% respectively, OR 0.66, 95\% CI: 0.41-1.00). According to the literature, tumor size seems by far the most powerful predictor of ALN involvement [1, 6, 20, 21] but histology (ILC versus non-ILC) is at least as important in our multivariate ALN/SLN model as independent prognostic factor (Table 4).

Secondly, genes involved in the metastatic process of ILCs might be different from those involved in non-ILC. Yoder stated that ILC are thought to arise from the same cell type as infiltrating ductal carcinoma with distinct genomic changes resulting in a different phenotype. Based on these genetic findings, loss of E-cadherin has become a widely used IHC parameter to diagnose ILCs. All our ILC cases were confirmed E-cadherin negative. However, retention of E-cadherin in ILC is rare and loss of E-cadherin in non-ILCs has been described in 7.2\% of non-ILCs [22, 23] without an impact on ALN status and therefore unlikely to affect our results.

Thirdly, ALN involvement may be a function of tumor volume/surface area rather than tumor diameter. Theoretic models have shown that the propensity for metastases depends on the total number of cells of a tumor combined with the probability of each individual cell to disseminate [24]. As tumors of similar diameter are different three-dimensional objects, the number of cells might be better estimated by three-dimensional parameters such as tumor volume than by a linear measurement. Tumor volume or cell load and even microvessel density may differ between ILCs and non-ILCs. Recent data does not support the assumption that three-dimensional measurements have an improved prognostic capability in comparison with traditional onedimensional measurements. Lobular carcinomas however, were excluded from analysis because in many cases, there is no grossly well-demarked mass, and therefore three-dimensional assessment of size is imprecise [25].

ALN is the best independent prognostic factor for disease-free and overall survival of breast cancer. Our findings of a lower likelihood for cell migration towards lymph nodes are in line with previous and more recent reports which suggested that prognosis is better for patients with ILC than for those with invasive ductal 
adenocarcinoma after matching for tumor stage [7, 26-28]. Both types of carcinoma are usually managed with the same adjuvant strategy which may be over-treatment for ILC as they are less systemically aggressive.

In conclusion, the present study demonstrates that the lobular subtype is an independent predictor for lymph node involvement with lobular cancer having a lower incidence of involved lymph nodes. The higher incidence of lymph node metastasis in lobular cancers in univariable analysis is not due to the lobular subtype, but to confounding factors that interact with lymph node involvement. 


\section{$\underline{\text { References }}$}

1. Patani NR, Dwek MV, Douek M: Predictors of axillary lymph node metastasis in breast cancer: a systematic review. Eur J Surg Oncol 2007, 33(4):409-419.

2. Arpino G, Bardou VJ, Clark GM, Elledge RM: Infiltrating lobular carcinoma of the breast: tumor characteristics and clinical outcome. Breast Cancer Res 2004, 6(3):R149-156.

3. Cristofanilli M, Gonzalez-Angulo A, Sneige N, Kau SW, Broglio K, Theriault RL, Valero V, Buzdar AU, Kuerer H, Buccholz TA et al: Invasive lobular carcinoma classic type: response to primary chemotherapy and survival outcomes. J Clin Oncol 2005, 23(1):41-48.

4. Pestalozzi BC, Zahrieh D, Mallon E, Gusterson BA, Price KN, Gelber RD, Holmberg SB, Lindtner J, Snyder R, Thurlimann B et al: Distinct clinical and prognostic features of infiltrating lobular carcinoma of the breast: combined results of 15 International Breast Cancer Study Group clinical trials. J Clin Oncol 2008, 26(18):3006-3014.

5. Tubiana-Hulin M, Stevens D, Lasry S, Guinebretiere JM, Bouita L, Cohen-Solal C, Cherel P, Rouesse J: Response to neoadjuvant chemotherapy in lobular and ductal breast carcinomas: a retrospective study on $\mathbf{8 6 0}$ patients from one institution. Ann Oncol 2006, 17(8):1228-1233.

6. Viale G, Zurrida S, Maiorano E, Mazzarol G, Pruneri G, Paganelli G, Maisonneuve P, Veronesi U: Predicting the status of axillary sentinel lymph nodes in 4351 patients with invasive breast carcinoma treated in a single institution. Cancer 2005, 103(3):492-500.

7. Wasif N, Maggard MA, Ko CY, Giuliano AE: Invasive lobular vs. ductal breast cancer: a stagematched comparison of outcomes. Ann Surg Oncol 2010, 17(7):1862-1869.

8. Neven P, Van Calster B, Van den Bempt I, Van Huffel S, Van Belle V, Hendrickx W, Decock J, Wildiers H, Paridaens R, Amant F et al: Age interacts with the expression of steroid and HER2 receptors in operable invasive breast cancer. Breast Cancer Res Treat 2008, 110(1):153159. 
9. Hastie T, Tibshirani R: Generalized additive models, 1st edn. London ; New York: Chapman and Hall; 1990.

10. Tubiana M: [Benefits and limitations of mass screening. The natural history of breast cancer]. Bull Acad Natl Med 1998, 182(8):1593-1610; discussion 1610-1591.

11. Bevilacqua JL, Kattan MW, Fey JV, Cody HS, 3rd, Borgen PI, Van Zee KJ: Doctor, what are my chances of having a positive sentinel node? A validated nomogram for risk estimation. $J$ Clin Oncol 2007, 25(24):3670-3679.

12. Voogd AC, Repelaer van Driel OJ, Roumen RM, Crommelin MA, van Beek MW, Coebergh JW: Changing attitudes towards breast-conserving treatment of early breast cancer in the south-eastern Netherlands: results of a survey among surgeons and a registry-based analysis of patterns of care. Eur J Surg Oncol 1997, 23(2):134-138.

13. Gann PH, Colilla SA, Gapstur SM, Winchester DJ, Winchester DP: Factors associated with axillary lymph node metastasis from breast carcinoma: descriptive and predictive analyses. Cancer 1999, 86(8):1511-1519.

14. Olivotto IA, Jackson JS, Mates D, Andersen S, Davidson W, Bryce CJ, Ragaz J: Prediction of axillary lymph node involvement of women with invasive breast carcinoma: a multivariate analysis. Cancer 1998, 83(5):948-955.

15. Velanovich V, Szymanski W: Lymph node metastasis in breast cancer: common prognostic markers lack predictive value. Ann Surg Oncol 1998, 5(7):613-619.

16. Voogd AC, Coebergh JW, Repelaer van Driel OJ, Roumen RM, van Beek MW, Vreugdenhil A, Crommelin MA: The risk of nodal metastases in breast cancer patients with clinically negative lymph nodes: a population-based analysis. Breast Cancer Res Treat 2000, 62(1):6369.

17. Sastre-Garau X, Jouve M, Asselain B, Vincent-Salomon A, Beuzeboc P, Dorval T, Durand JC, Fourquet A, Pouillart P: Infiltrating lobular carcinoma of the breast. Clinicopathologic 
analysis of 975 cases with reference to data on conservative therapy and metastatic patterns. Cancer 1996, 77(1):113-120.

18. Cserni G: Histopathologic examination of the sentinel lymph nodes. Breast J 2006, 12(5 Suppl 2):S152-156.

19. Patil DT, Susnik B: Keratin immunohistochemistry does not contribute to correct lymph node staging in patients with invasive lobular carcinoma. Hum Pathol 2008, 39(7):10111017.

20. Maiorano E, Regan MM, Viale G, Mastropasqua MG, Colleoni M, Castiglione-Gertsch M, Price KN, Gelber RD, Goldhirsch A, Coates AS: Prognostic and predictive impact of central necrosis and fibrosis in early breast cancer: results from two International Breast Cancer Study Group randomized trials of chemoendocrine adjuvant therapy. Breast Cancer Res Treat, 121(1):211-218.

21. Zurrida S, Morabito A, Galimberti V, Luini A, Greco M, Bartoli C, Raselli R, Rossi N, Vessecchia $\mathrm{G}$, Cascinelli $\mathrm{N}$ et al: Importance of the level of axillary involvement in relation to traditional variables in the prognosis of breast cancer. Int J Oncol 1999, 15(3):475-480.

22. Da Silva L, Parry S, Reid L, Keith P, Waddell N, Kossai M, Clarke C, Lakhani SR, Simpson PT: Aberrant expression of E-cadherin in lobular carcinomas of the breast. Am J Surg Pathol 2008, 32(5):773-783.

23. Rakha EA, Abd El Rehim D, Pinder SE, Lewis SA, Ellis IO: E-cadherin expression in invasive non-lobular carcinoma of the breast and its prognostic significance. Histopathology 2005, 46(6):685-693.

24. Michaelson JS, Silverstein M, Wyatt J, Weber G, Moore R, Halpern E, Kopans DB, Hughes K: Predicting the survival of patients with breast carcinoma using tumor size. Cancer 2002, 95(4):713-723. 
25. Verkooijen HM, Fioretta G, Vlastos G, Morabia A, Schubert H, Sappino AP, Pelte MF, Schafer P, Kurtz J, Bouchardy C: Important increase of invasive lobular breast cancer incidence in Geneva, Switzerland. Int J Cancer 2003, 104(6):778-781.

26. Dixon AR, Ellis IO, Elston CW, Blamey RW: A comparison of the clinical metastatic patterns of invasive lobular and ductal carcinomas of the breast. Br J Cancer 1991, 63(4):634-635.

27. Gudlaugsson E, Skaland I, Janssen EA, van Diest PJ, Voorhorst FJ, Kjellevold K, zur Hausen A, Baak JP: Prospective multicenter comparison of proliferation and other prognostic factors in lymph node negative lobular invasive breast cancer. Breast Cancer Res Treat 2010, 121(1):35-40.

28. Toikkanen S, Pylkkanen L, Joensuu H: Invasive lobular carcinoma of the breast has better short- and long-term survival than invasive ductal carcinoma. Br J Cancer 1997, 76(9):12341240.

Table 1: Patient and tumor characteristics according to the histologic subtype

\begin{tabular}{|c|c|c|c|c|}
\hline Variable & Statistic & ILC & non-ILC & $\mathbf{P}$ \\
\hline \multicolumn{5}{|l|}{ Grade } \\
\hline 1 & $\mathrm{~N}(\mathrm{col} \%)$ & $7(1.3)$ & $633(17.0)$ & $<0.001^{\mathrm{a}}$ \\
\hline 2 & $\mathrm{~N}(\operatorname{col} \%)$ & $476(85.5)$ & $1445(38.7)$ & \\
\hline 3 & $\mathrm{~N}(\operatorname{col} \%)$ & $74(13.3)$ & $1657(44.4)$ & \\
\hline \multicolumn{5}{|l|}{ ER, PR, HER-2 } \\
\hline ER-PR-Her-2- & $\mathrm{N}(\operatorname{col} \%)$ & $7(1.3)$ & 419 (11.2) & $<0.001$ \\
\hline ER-PR-Her-2+ & $\mathrm{N}(\operatorname{col} \%)$ & $4(0.7)$ & $181(4.9)$ & \\
\hline ER+PR-Her-2- & $\mathrm{N}(\operatorname{col} \%)$ & $56(10.1)$ & $347(9.3)$ & \\
\hline$E R+P R-H e r-2+$ & $\mathrm{N}(\operatorname{col} \%)$ & $2(0.4)$ & $89(2.4)$ & \\
\hline$E R+P R+H e r-2-$ & $\mathrm{N}(\operatorname{col} \%)$ & $475(85.3)$ & $2502(67.0)$ & \\
\hline$E R+P R+H e r-2+$ & $\mathrm{N}(\operatorname{col} \%)$ & $13(2.3)$ & $197(5.3)$ & \\
\hline Multifocality & $\mathrm{N}(\operatorname{col} \%)$ & $88(15.8)$ & $374(10.0)$ & $<0.001$ \\
\hline Age (years) & Median (IQR) & $59(50-68)$ & $57(49-67)$ & $0.001^{b}$ \\
\hline Tumor size (mm) & Median (IQR) & $30(17-50)$ & $20(14-30)$ & $<0.001^{\mathrm{b}}$ \\
\hline
\end{tabular}


${ }^{\text {a }}$ Kendall's tau test

${ }^{\mathrm{b}}$ Wilcoxon rank sum test

Table 2: Univariable prediction of ALN involvement

\begin{tabular}{|c|c|c|c|c|c|}
\hline Variable & Statistic & $\mathbf{L N +}$ & LN- & $\begin{array}{c}\text { Odds Ratio of } \mathrm{LN}+ \\
(95 \% \mathrm{CI})\end{array}$ & $\mathbf{P}$ \\
\hline \multicolumn{6}{|l|}{ Histology } \\
\hline$I L C$ & $\mathrm{~N}($ row \%) & $234(42.0)$ & $323(58.0)$ & ILC vs non-ILC: & \multirow{2}{*}{0.093} \\
\hline non-ILC & $\mathrm{N}($ row \%) & $1430(38.3)$ & $2305(61.7)$ & $1.17(0.97-1.40)$ & \\
\hline \multicolumn{6}{|l|}{ Grade } \\
\hline 1 & $\mathrm{~N}($ row \%) & $161(25.2)$ & $479(74.8)$ & Vs grade 1: & \multirow{3}{*}{$<0.001$} \\
\hline 2 & $\mathrm{~N}($ row \%) & $720(37.5)$ & $1201(62.5)$ & $1.78(1.46-2.19)$ & \\
\hline 3 & $\mathrm{~N}$ (row \%) & $783(45.2)$ & $948(54.8)$ & $2.46(2.01-3.01)$ & \\
\hline \multicolumn{6}{|l|}{ ER, PR, HER-2 } \\
\hline ER-PR-Her-2- & $\mathrm{N}($ row \%) & $148(34.7)$ & $278(65.3)$ & Vs ER- PR- Her-2-: & \multirow{6}{*}{0.005} \\
\hline ER-PR-Her-2+ & $\mathrm{N}($ row \%) & $86(46.5)$ & $99(53.5)$ & $1.63(1.15-2.32)$ & \\
\hline$E R+P R-H e r-2-$ & $\mathrm{N}($ row \%) & $149(37.0)$ & $254(63.0)$ & $1.10(0.83-1.46)$ & \\
\hline ER + PR-Her $-2+$ & $\mathrm{N}($ row $\%)$ & $34(37.0)$ & $57(63.0)$ & $1.12(0.70-1.78)$ & \\
\hline$E R+P R+H e r-2-$ & $\mathrm{N}($ row \%) & $1145(38.5)$ & $1832(61.5)$ & $1.17(0.95-1.46)$ & \\
\hline ER + PR + Her $-2+$ & $\mathrm{N}($ row \%) & $102(48.6)$ & $108(51.4)$ & $1.77(1.27-2.49)$ & \\
\hline \multicolumn{6}{|l|}{ Multifocal } \\
\hline unifocal & $\mathrm{N}($ row $\%)$ & $1448(37.8)$ & $2382(62.2)$ & Multi- vs unifocal: & \multirow{2}{*}{$<0.001$} \\
\hline multifocal & $\mathrm{N}$ (row \%) & $216(46.8)$ & $246(53.3)$ & $1.44(1.19-1.75)$ & \\
\hline Age & Median (IQR) & $56(48-66)$ & $58(49-67)$ & $\begin{array}{c}0.97 \text { per } 10 \text { year } \\
(0.92-1.02)\end{array}$ & 0.174 \\
\hline Tumor size (mm) & Median (IQR) & $30(20-45)$ & $19(12-26)$ & $\begin{array}{l}1.52 \text { per } \mathrm{cm} \\
(1.46-1.59)\end{array}$ & $<0.001$ \\
\hline
\end{tabular}

Table 3: Univariable prediction of ALN involvement for SLN patients only.

\begin{tabular}{lccccc}
\hline Variable & Statistic & LN+ & LN- & $\begin{array}{c}\text { Odds Ratio of LN+ } \\
\text { (95\% CI) }\end{array}$ & P \\
\hline $\begin{array}{l}\text { Histology } \\
I L C\end{array}$ & & & & & \\
$\quad$ Non-ILC & N (row \%) & $27(20.5)$ & $105(79.5)$ & ILC vs non-ILC: & 0.056 \\
$\begin{array}{l}\text { Grade } \\
\quad\end{array}$ & & $389(28.3)$ & $985(71.7)$ & $0.65(0.41-1.00)$ & \\
\hline
\end{tabular}




\begin{tabular}{|c|c|c|c|c|c|}
\hline 2 & $\mathrm{~N}($ row $\%)$ & $191(27.3)$ & $508(72.7)$ & $1.11(0.82-1.50)$ & \\
\hline 3 & $\mathrm{~N}($ row $\%)$ & $144(29.5)$ & $344(70.5)$ & $1.23(0.90-1.70)$ & \\
\hline \multicolumn{6}{|l|}{ ER, PR, HER-2 } \\
\hline ER-PR-Her-2- & $\mathrm{N}($ row \%) & $27(20.5)$ & $105(79.6)$ & Vs ER- PR- Her-2-: & \multirow{6}{*}{0.309} \\
\hline ER-PR-Her-2+ & $\mathrm{N}($ row \%) & $10(29.4)$ & $24(70.6)$ & $1.62(0.67-3.73)$ & \\
\hline$E R+P R-H e r-2-$ & $\mathrm{N}($ row \%) & $36(27.7)$ & $94(72.3)$ & $1.55(0.88-2.75)$ & \\
\hline ER + PR - Her $-2+$ & $\mathrm{N}($ row \%) & $4(15.4)$ & $22(84.6)$ & $0.71(0.20-2.04)$ & \\
\hline$E R+P R+H e r-2-$ & $\mathrm{N}($ row \%) & $320(28.6)$ & $798(71.4)$ & $1.57(1.02-2.48)$ & \\
\hline$E R+P R+H e r-2+$ & $\mathrm{N}($ row \%) & $19(28.8)$ & $47(71.2)$ & $1.57(0.79-3.10)$ & \\
\hline \multicolumn{6}{|l|}{ Multifocal } \\
\hline unifocal & $\mathrm{N}($ row \%) & $380(27.1)$ & $1020(72.9)$ & Multi- vs unifocal: & \multirow{2}{*}{0.131} \\
\hline multifocal & $\mathrm{N}($ row \%) & $36(34.0)$ & $70(66.0)$ & $1.38(0.90-2.09)$ & \\
\hline Age & Median (IQR) & $57(50-65)$ & $57(49-66)$ & $\begin{array}{l}1.02 \text { per } 10 \text { year } \\
\quad(0.92-1.12)\end{array}$ & 0.656 \\
\hline Tumor size (mm) & Median (IQR) & $20(15-25)$ & $15(10-20)$ & $\begin{array}{l}1.53 \text { per } \mathrm{cm} \\
(1.37-1.72)\end{array}$ & $<0.001$ \\
\hline
\end{tabular}

Table 4: Multivariable logistic regression predicting ALN involvement for all patients and for the SLN patients separately

\begin{tabular}{|c|c|c|c|c|c|c|}
\hline \multirow[b]{2}{*}{ Variable } & \multicolumn{3}{|c|}{ ALL PATIENTS } & \multicolumn{3}{|c|}{ SLN SUBGROUP } \\
\hline & Coefficient & $\begin{array}{c}\text { Odds Ratio } \\
\text { (95\% CI })\end{array}$ & $\mathbf{P}$ & Coefficient & $\begin{array}{c}\text { Odds Ratio } \\
(95 \% \text { CI })\end{array}$ & $\mathbf{P}$ \\
\hline ILC & -0.421 & $\begin{array}{c}0.66 \\
(0.53-0.82)\end{array}$ & $<0.001$ & -0.722 & $\begin{array}{c}0.49 \\
(0.30-0.78)\end{array}$ & 0.003 \\
\hline \multicolumn{7}{|l|}{ Grade } \\
\hline 1 & \multicolumn{2}{|c|}{ Reference level } & & \multicolumn{2}{|c|}{ Reference level } & \\
\hline 2 & 0.314 & $\begin{array}{c}1.37 \\
(1.10-1.71)\end{array}$ & $<0.001$ & 0.091 & $\begin{array}{c}1.10 \\
(0.80-1.51)\end{array}$ & 0.714 \\
\hline 3 & 0.550 & $\begin{array}{c}1.72 \\
(1.38-2.18)\end{array}$ & & 0.151 & $\begin{array}{c}1.16 \\
(0.81-1.67)\end{array}$ & \\
\hline \multicolumn{7}{|l|}{ ER, PR, HER-2 } \\
\hline ER-PR-Her-2- & \multicolumn{2}{|c|}{ Reference level } & & \multicolumn{2}{|c|}{ Reference level } & \\
\hline ER-PR-Her-2+ & 0.436 & $\begin{array}{c}1.55 \\
(1.06-2.25)\end{array}$ & 0.005 & 0.516 & $\begin{array}{c}1.68 \\
(0.67-3.98)\end{array}$ & 0.183 \\
\hline$E R+P R-H e r-2-$ & 0.350 & $\begin{array}{c}1.42 \\
(1.04-1.94)\end{array}$ & & 0.557 & $\begin{array}{c}1.75 \\
(0.95-3.23)\end{array}$ & \\
\hline
\end{tabular}




\begin{tabular}{|c|c|c|c|c|c|c|}
\hline ER+PR-Her $-2+$ & 0.219 & $\begin{array}{c}1.25 \\
(0.76-2.03)\end{array}$ & & -0.313 & $\begin{array}{c}0.73 \\
(0.20-2.15)\end{array}$ & \\
\hline$E R+P R+H e r-2-$ & 0.415 & $\begin{array}{c}1.51 \\
(1.19-1.93)\end{array}$ & & 0.571 & $\begin{array}{c}1.77 \\
(1.10-2.92)\end{array}$ & \\
\hline$E R+P R+H e r-2+$ & 0.669 & $\begin{array}{c}1.95 \\
(1.37-2.79)\end{array}$ & & 0.609 & $\begin{array}{c}1.84 \\
(0.91-3.69)\end{array}$ & \\
\hline Multifocality & 0.466 & $\begin{array}{c}1.60 \\
(1.30-1.96)\end{array}$ & $<0.001$ & 0.372 & $\begin{array}{c}1.45 \\
(0.93-2.24)\end{array}$ & 0.097 \\
\hline Age & -0.003 & $\begin{array}{c}0.97 \text { per } 10 \text { year } \\
(0.92-1.02)\end{array}$ & 0.206 & 0.003 & $\begin{array}{c}1.03 \text { per } 10 \text { year } \\
(0.93-1.14)\end{array}$ & 0.604 \\
\hline Tumor size $(\mathrm{cm})$ & 0.422 & $\begin{array}{l}1.53 \text { per } \mathrm{cm} \\
(1.46-1.60)\end{array}$ & $<0.001$ & 0.433 & $\begin{array}{l}1.54 \text { per } \mathrm{cm} \\
(1.37-1.73)\end{array}$ & $<0.001$ \\
\hline
\end{tabular}

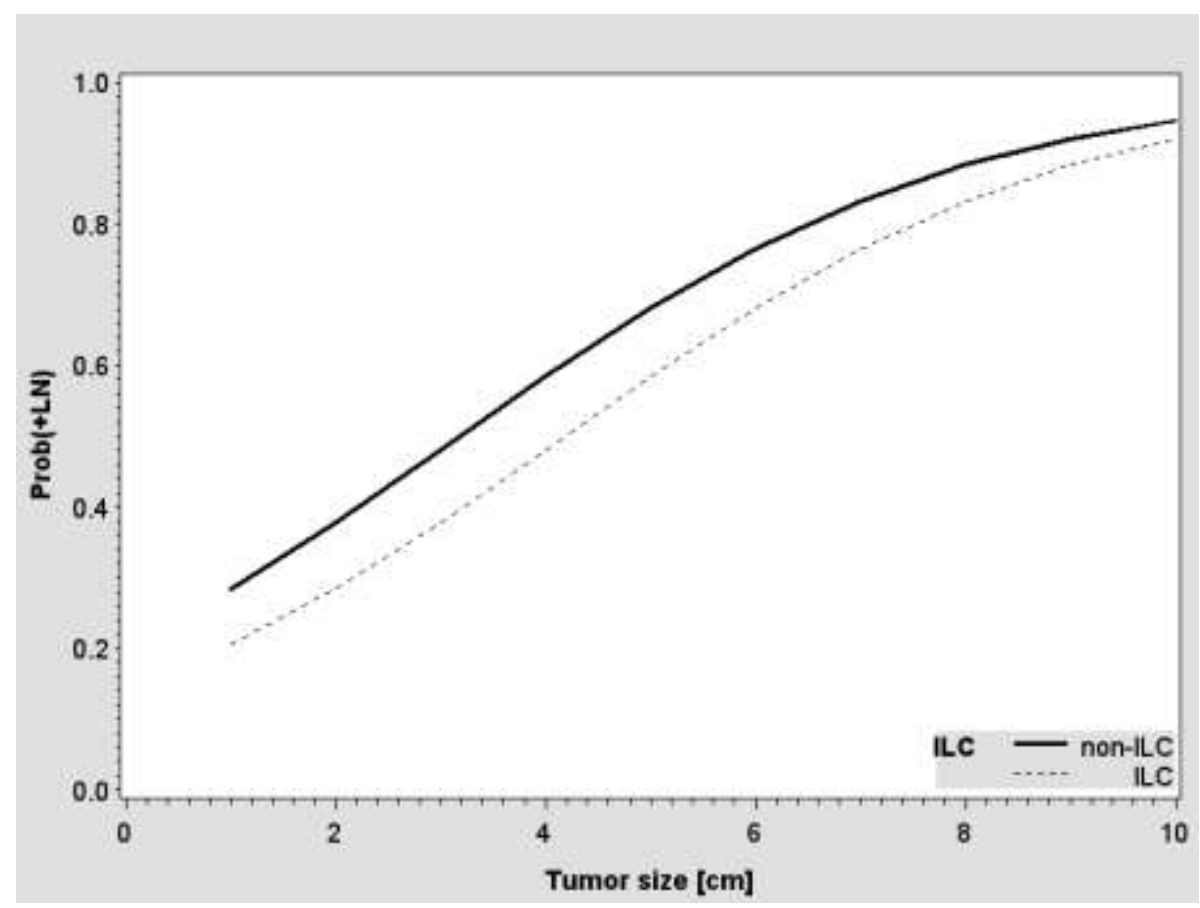

Figure 1: Multivariable logistic regression: Probability of ALN involvement vs. tumor size. Full and dashed plot lines are model predictions for respectively non-ILC and ILC tumors with the following fixed characteristics: grade II, unifocal, ER+, PR+, HER-2- for age 58. 


\section{Copyright Transfax Statemẹnt \\ BREAST CANGER RESEMRCH AND TKEATMERT}

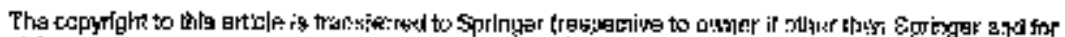

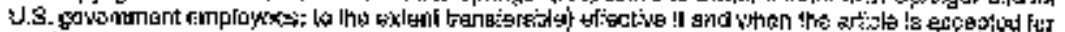

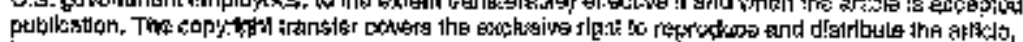

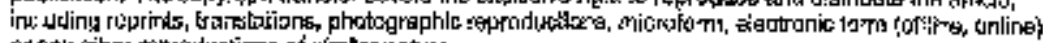

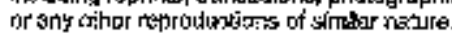

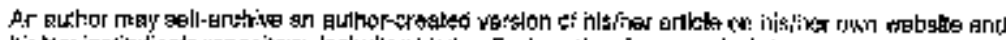

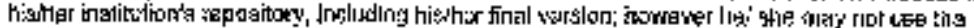

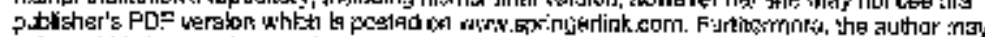

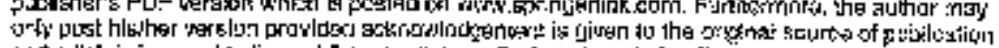

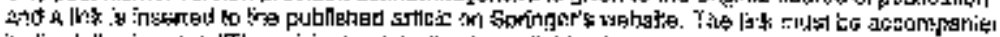

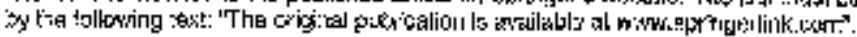

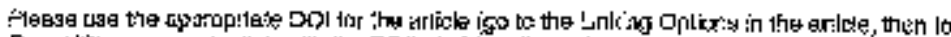

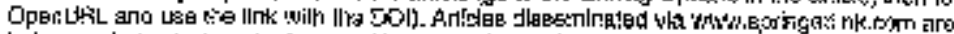

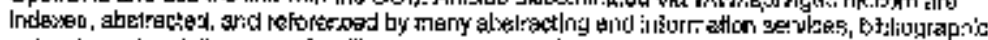

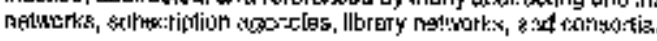

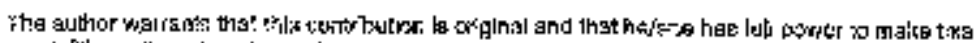

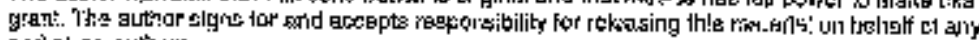

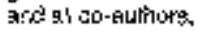

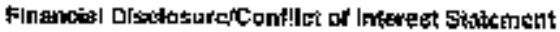

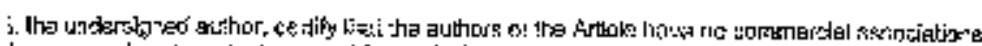

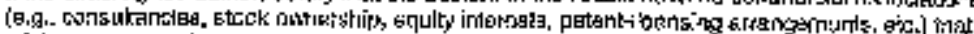

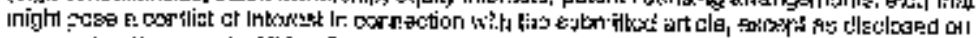

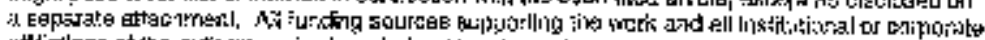

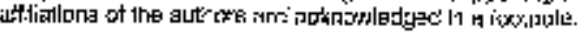

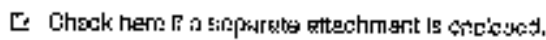

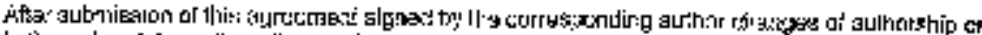

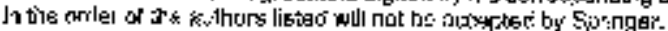

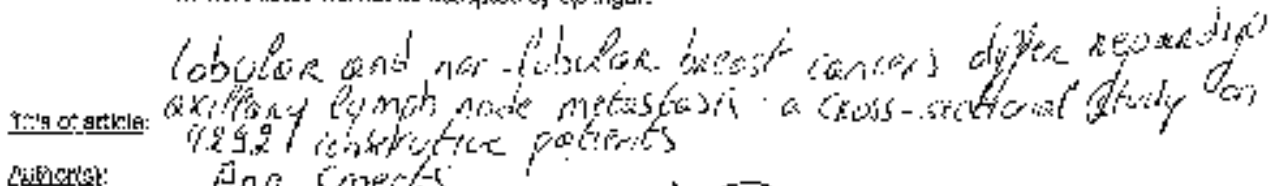

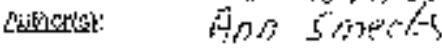

Authuresingetsin:

late find

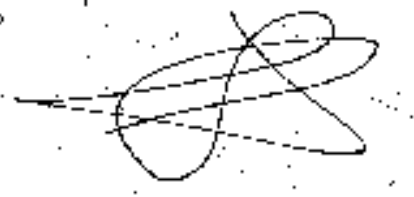

